\title{
The Development of University Students' Cognitive Activity as a Part of Human Capital Growth in Kuzbass Mining Cluster
}

\author{
Natalia Deryabina ${ }^{1}$, and Tatyana Sergeichik ${ }^{1, *}$ \\ ${ }^{1}$ Kemerovo State University, 650000, 6 Krasnaya st., Kemerovo, Russia
}

\begin{abstract}
Social and economic welfare in Kuzbass as a coal mining region is provided through the development of human capital. This task is accomplished via education and training, enabling improved levels of quality and production at coal mining enterprises. Therefore, the increasing requirements for University graduates imply the need of new forms and updated content in students' cognitive activity development. The main goal of our research is to identify and justify the conditions for developing students' cognitive activity in the process of their studying at the University in coal mining region. The article presents data from a study carried out among students and teachers of Kemerovo State University, the largest institution of higher education in Kuzbass. During the research, special attention was paid to implementing the problem-based learning, which allowed students to enhance their activities at lectures, seminars, and in preparing for classes. The results of the study showed progress in students' independent cognitive activity and their self-motivated attitude to the process of learning due to several factors. The activity of students largely depends on the teachers' proficiency in supporting, guiding, and monitoring the learning process, as well as on the teaching methods they use. The growth of human capital in terms of higher education becomes a key determinant of the coal mining region's sustainable development.
\end{abstract}

\section{Introduction}

Education has always been one of the most influential spheres in the development of society. In the last decade, the world has changed its attitude to all types of education. Education, especially higher education, is considered as a key attribute of social as well as economic progress, and is associated with long-term improvements in economic performance. Nowadays, it is common to take into account one more correlative economic growth factor such as human capital which depends largely on the trends and efficiency of education. The reason for this attention is the understanding that the most important value and the main capital of modern society is a person who is interested in knowledge acquisition, able to search for new ideas, and make non-standard decisions.

Theory and practice of psychology and pedagogy prove that extracting, structuring and organizing knowledge along with developing skills to find solutions to problems by

*Corresponding author: 1alli8@mail.ru 
students are possible only as a result of their intensive cognitive activity. The common examples of cognitive activities are reasoning, thinking, perceiving, listening, observing, etc. High-level cognitive activities usually include problem solving, decision making, and sense making that involve using and working with information.

Under current conditions, in the context of modernization of the higher education system and increasing requirements for University graduates, the students' cognitive activity is filled with new content. The University should provide such educational environment that allows students to master the skills of independent cognitive activity, encourages the development of the individual's creativity, and contributes to the advance in the student's critical appraisal.

However, despite the substantial advances in the Russia's higher education system, developing students' cognitive activity has not yet become a priority for many University teachers, which, of course, reduces the chances of the students' career success. Not all universities adequately complete the crucial pedagogical and social task of developing students' cognitive interests. The main focus continues to be on broadening the scope of learning content, which makes students overloaded, and hinders the development of independent creative thinking skills.

The leading factors preventing from the development of students' cognitive activity, in University teachers' opinion, are the students' academic failure in secondary school (or low levels of secondary education) along with their poor development of independent work skills, weak self-organization of students, lack of teaching skills and strategies, poor material base.

\section{Materials and methods}

The research was carried out at Kemerovo State University from 2015 to 2019. 276 students of the first, second and third year of study and 104 teachers from different departments at Kemerovo State University took part in this research.

In preparing the study the following research methods were used: literature review on theoretical issues in psychology and pedagogy, observation, questioning, interviewing, testing, individual and group conversations with students and teachers, qualitative synthesis (qualitative systematic review).

\section{Results and discussion}

The task of the first stage of research was to assess how much students were involved in classroom activities, and to determine the reasons for the insufficient classroom participation of several students. The study showed that only $18 \%$ of students responded that they were completely involved in the classroom activities; $72 \%$ of students responded that their classroom participation was sufficient depending on the situation; $10 \%$ of students considered themselves as passive listeners in the classroom.

In addition, to assess students' prior knowledge and skills in the first and second year of their University studies, we used achievement tests, i.e. standardized tests that allowed to measure skills and knowledge learned in a given grade level, as well as special competency development among future specialists for Kuzbass coal mining enterprises. The tests made it possible to check students' skills and knowledge attained in a course, to analyze the most common fails and faults, including their reasons.

We divided the total number of the responses received as a result of testing students in all academic disciplines into three groups. The first group includes students' papers 
containing from $70 \%$ to $100 \%$ correct answers; the second group - from $40 \%$ to $69 \%$; and the third group - from $0 \%$ to $39 \%$ correct answers.

The data showed that students at the beginning of our work had low (58.6\%) and average $(32.4 \%)$ levels of prior knowledge. Only 9\% of students had a high level of reference knowledge. These were the conditions in which we started to go for the main goal of our research - to determine and justify the conditions for developing students' cognitive activity at Kemerovo State University.

Many scientists qualify the use of problem-based learning and independent work as an important way of organizing students' cognitive activity. In their opinion, problem-based learning is the basis for cognitive development. Along with this, it is important to take into consideration that independent work is a form of implementing problem-based learning.

In the current context, it is not possible to consider the process of studying at a University only as a well-established mechanism for imparting knowledge from a teacher to a student, which is transformed into skills according to pre-set rules. It is necessary to teach students to master the ways of acquiring knowledge and methods of searching for new information and ideas [2]. However, when working with the first year students who demonstrated a low level of prior knowledge, we had to start the educational process with the use of informational training methods, since this was the only way we could improve the level of their prior knowledge.

The adequate level of prior knowledge is needed to implement problem-based learning. It was only when we reached this level that we started organizing problem-based learning. At the same time, it is important to note that we had to use this approach at the beginning of each course, and regardless of the year of bachelor's studies.

Implementing problem-based learning made it possible to change the students' attitude to activities at lectures, seminars, practical classes, as well in preparing for their classes. Problem-based learning was incorporated in the form of collaborative activity of teachers and students, which was aimed at dealing with the real-life scenarios and practical tasks. Having the experience of solving open-ended problems, students learned to independently reason, critically appraise and search for the right resolution.

To promote the students' cognitive activity in the classroom, we constructed trigger situations such as surprise, conflict, assumption, inconsistencies, controversy, uncertainty, etc.

Promoting cognitive development through problem-based learning consisted not only in a proper selection of problems and trigger situations, but also in timely teacher's facilitation by guiding, supporting, and monitoring the whole process of problem solving, as well as providing students' involvement in collaboration [8].

The most common method of teaching in the educational process of the University is lecture. It has a leading role in developing students' cognitive activity. We used an approach in which a lecture became a form of collaborative reflection and discussion of the lecturer and students - addressed the challenging issues and stimulated to find the solution to them, taught students to search for the necessary resources and operate the information.

An important clause for the development of cognitive activity was the student's participation in the search for answers to the teacher's questions, as well as the students' questions to the teacher for a deeper understanding of the subject being taught at lecture. If a student during a lecture sought to answer the teacher's questions or asked him about certain statements heard, this was a sign of the student's curiosity, a reflection of his cognitive activity.

In the process of training specialists at Kemerovo State University, we paid special attention to combining theoretical knowledge retained at lectures and seminars with externships. This was crucial to provide students with short practical experiences in their field of study and dealing with day-to-day routines [6]. Externships revealed the gaps in 
students' knowledge or skills; increased the importance of theoretical knowledge in special subjects; gave students the opportunity to apply their knowledge or to check the validity of the acquired knowledge, as well as to target students to further consideration of theoretical issues. So, at lecture the teacher had to guide the students' cognitive activity from theory to practice and from practice to theory.

The content of lectures and independent work of students was closely connected with that of seminars. So, a seminar class became a kind of laboratory for creativity, where the students' knowledge acquired at lectures and during their independent activity was solidified, deepened, advanced - promoting the students' cognitive activity from a lower level to a higher one. Seminar classes also served as a method of monitoring and progress evaluation.

By constructing problem situations, we organized an intensive educational activities of students at lectures, seminars and other classes. We also encouraged students to ask questions and construct problem situations in classrooms [3, 10].

It is interesting to mention that at the beginning of the research $65 \%$ of students made up questions and constructed the so-called reproductive problem situations, that required only to retell a text or reproduce some information from a source; but, by the end of the research, the number of such students decreased to $4 \%$. Moreover, at the beginning of the study, no student raised questions for group discussion that required the introduction of new issues. However, by the end of the research, there were $19 \%$ of such students who initiated the discussion of complicated problem situations. The obtained data allowed us to conclude that the efforts in students' independent cognitive activity increased significantly by the end of the research.

The development of students' cognitive activity also stood upon teachers' skillful use of tasks [4] to promote creative thinking among students - designing experiments, preparing abstracts, writing reports, etc. Among striking examples of such tasks we used educational games, role-playing, and business simulation games.

For example, the teachers from the Department of Mathematics successfully used recreational mathematics tasks, test tasks for educational games on such topics as "Probability Theory", "Basic Elements of Linear and Vector Algebra", "Integral", "Differential equations", etc. Students were offered rhymed texts, where instead of spaces they had to insert the proper formula, equation or draw a graph.

Students were particularly interested in the use of matrix tests, tests called "Sieve", in which a theorem, for example, was created and proved with spaces. To fill in these gaps, the students needed to learn the content of the current class along with the earlier studied topics.

At the Department of Economics, in order to promote students' cognitive development along with strategic thinking skills, a computer business simulation game "Nixdorf Delta" was introduced into the educational process. The business simulation game was based on a virtual model of an enterprise, whose operating conditions were determined by a set of integrated parameters that produced changes in both the internal and external environment of the enterprise. Using theoretical knowledge acquired in the study of economics subjects, students were able to master the skills of analytical market research, managing resources, production planning, and financial analysis of the business.

The business simulation game provided teachers and students with a wide range of opportunities to organize seminar classes in a variety of forms and content combinations, as well as carry out research in business model construction, marketing strategies development in different market conditions. Students obtained their own experience, learning the different aspects of enterprise management in a constantly changing market environment. This improved their knowledge and professional skills in the field of economics and management. 
The development of students' cognitive activity at Kemerovo State University required their systematic persistent independent work. We considered the concept of "independent work" as not only a homework, but as a set of all student's activities to improve his competencies without the direct participation of a teacher, but with facilitating role of a teacher in case of difficulty [1]. Students' independent activity took place both in the classroom and extracurricular studies.

Students were given instructions aimed at developing their skills to tackle literature, work with books, reference materials, the Internet and other sources. Also we drew up practical guidelines to help students with the choice of methods to work on literature $[5,7]$. These were used in combination with teacher's consultations about different methods of learning and reading. This approach gradually changed the attitude of students to classroom activities.

The important part of the students' cognitive development process was the objective assessment of students' knowledge and skills, as well as their competences acquired in the course of classroom cognitive activity. The current progress testing was implemented to check students' knowledge on a particular subject. Completing such achievement tests promoted the students' intellectual activity, allowing them to keep their attention on learning the entire course as hard as possible.

The examination tests included several theoretical tasks, where students had to add a formula, word or sign, etc., as well as theorems with proofs written with spaces. The students had to insert the missing symbols so that the theorems were read correctly. The performance of an examinee on each test task was conveyed in scores. The maximum score corresponded to an excellent mark. This test was taken by students at the end of the first semester. The content of the examination tests for the first and subsequent semesters was determined by the topics taught during the semester, and met the requirements of the current program in further mathematics for technical universities.

In addition, teachers of the Department of Further Mathematics developed an electronic version of the examination tests, which is very popular among students, since during the exam they could consult textbooks in case of hesitation about the validity. A threedimensional color histogram appeared on the screen, showing the number of correct and incorrect responses. An unbiased computer assessment provided students with scores as well as with a comment on it, giving students the opportunity to analyze correct and incorrect answers.

As a form of control and self-control, examination tests in both versions (written and electronic) allowed to achieve an objective assessment of students' knowledge, increased the percentage of students' retained knowledge, provided a favorable psychological state for the majority of students during the examination session, and literally brought no conflict issues.

To promote students' cognitive activity development, a rating system for evaluating their knowledge has been used for several years, which, in our opinion, is one of the most objective [9]. According to students, this exam is "a semester long". The final score was the average value of students' grades for different types of tasks.

The obtained results showed that the level of students' classroom independent activity increased significantly by the end of our research. More precisely, at the beginning of the research, only $35 \%$ of students were able to manage time for their independent work effectively; however, by the end of the research, the number of such students increased to $76 \%$. We discovered that the number of students who acquired the skills of effective independent work with text material $(87 \%)$ and using technical learning tools $(82 \%)$ increased significantly. And the number of students seeking to quite independently acquire their knowledge in subjects increased to $73 \%$. 
The research showed, that it was possible to track changes in students' motivation in preparing for classes. So, at the beginning of our research, only $14 \%$ of students demonstrated their interest in studies. The number of such students increased to $64 \%$ by the end of the research. The percentage of students who studied regularly and realized the need to pass tests and exams on time increased by 2.1 and amounted to $47 \%$ and $59 \%$, respectively. At the beginning of the research, only $36 \%$ of students were conscious of the importance to acquire professional knowledge, but by the end of the study, the number of such students increased to $76 \%$.

\section{Conclusion}

So, the development of student' cognitive activity at the University of the coal mining region depends on how well they master the skills of acquiring educational knowledge. Therefore, students should be systematically taught to learn subjects at the institutions of higher education. The responsibility of the teacher is to advise students in the process of mastering new competencies, as well as to motivate students, since the joy of achieving good results stimulates their cognitive activity. Students' personal achievements, progress in their studies along with incentives from teachers contribute to encouraging volition and strength in dealing with difficulties. Therefore, we created special conditions in which students developed such qualities as perseverance, curiosity, persistence in achieving goals, entrepreneurship, and the skills of personal development and self-actualization. Recognition of the results of student's work and appreciation for his performance motivated students, formed high self-efficacy, the will to learn, and increased their ambitions.

That aside, students' ambitions also largely depend on the teacher's commitment and his personal potential, on his methods, tools and technologies he uses, on how pedagogically correctly he organizes the search activities of students, which can lead to success in their future profession at the coal mining enterprises of Kuzbass.

Cognitive activity development, which is essential for the individual's success in further acquiring knowledge and necessary skills, is required by all forms of employment.

The individual's success in further acquiring knowledge and necessary skills, as a result of cognitive activity development, is required by all forms of employment. Being a productive personality trait which promotes learning how to be creative, cognitive activity is an integral part of the human capital development. This develops a particular ability to complete innovative and complicated tasks of the business companies. Kemerovo State University contributes to the human capital growth in Kuzbass, which becomes a key determinant of the coal mining region's sustainable development.

\section{References}

1. E. G. Armstrong, A Hybrid Model of Problem-based Learning (Routledge, London, 2008)

2. Samy A. Azer, Medical Teacher, 33:10, 808-813 (2011)

3. D. Barnes, F. Todd, Communication and learning revisited: making meaning through talk (Boynton/Cook Publishers Inc, Portsmouth, 1995)

4. J. Clough, G. W. Shorter, The Law Teacher, 49:3, 227-302 (2015)

5. B. J. Duch, Susan E. Groh, Deborah E. Allen, The power of problem-based learning: $a$ practical "how to" for teaching undergraduate courses in any discipline (Stylus Pub., Sterling, 2001)

6. Kellah M. Edens, College Teaching, 48:2, 55-60 (2000) 
7. C. E. Hmelo, D. H. Evensen, IJCRR, 08:22, 22-24 (2000)

8. C. E. Hmelo-Silver, Educ Psychol Rev, 16:3, 235-266 (2004)

9. R. Islamov, T. Sergeychick, E3S Web Conf., 105, 04016 (2019)

10. S. E. Severiens, H. G. Schmidt, High Educ, 58, 59 (2009) 